\title{
A greenhouse gas indicator for bioenergy: some theoretical issues with practical implications
}

\author{
Jeroen B. Guinée • Reinout Heijungs • \\ Ester van der Voet
}

Received: 26 June 2008 / Accepted: 29 March 2009/Published online: 7 May 2009

(C) The Author(s) 2009. This article is published with open access at Springerlink.com

\begin{abstract}
Background, aim, and scope The expectations with respect to biomass as a resource for sustainable energy are skyhigh. Many industrialized countries have adopted ambitious policy targets and have introduced financial measures to stimulate the production or use of bioenergy. Meanwhile, the side-effects and associated risks have been pointed out as well. To be able to make a well-informed decision, the Dutch government has expressed the intention to include sustainability criteria into relevant policy instruments.

Main features Among other criteria, it has been proposed to calculate a so-called life-cycle-based greenhouse gas (GHG) indicator, which expresses the reduction of GHG emissions of a bio-based fuel chain in comparison with a fossil-based fuel chain. Life-cycle-based biofuel studies persistently have problems with the handling of biogenic carbon balances and with the treatment of coproducts and recycling. In life-cycle assessments (LCAs) of agricultural products, a distinction between "negative" and "positive" emissions may be relevant. In particular, carbon dioxide, as a naturally occurring compound or an anthropogenic emission, takes part in the so-called geochemical carbon cycle. The most appropriate way to treat carbon cycles is to view them as genuine cycles and, thus, at the systems level, subtract the fixation of $\mathrm{CO}_{2}$ during tree growth from the $\mathrm{CO}_{2}$ emitted during waste treatment of discarded wood and to quantify the $\mathrm{CH}_{4}$ emitted. In solving the multifunctionality problem, two steps may be distinguished. The first concerns the modeling of the product system studied in the
\end{abstract}

Responsible editor: Joerg Schweinle

J. B. Guinée $(\bowtie) \cdot$ R. Heijungs $\cdot$ E. van der Voet Institute of Environmental Sciences (CML), Leiden University, P.O. Box 9518, 2300 RA Leiden, The Netherlands e-mail: Guinee@cml.leidenuniv.nl inventory analysis. In this step, system boundaries are set, processes are described, and process flows are quantified. Multifunctionality problems can be identified and the model of the product system is drafted. The second step concerns solving the remaining multifunctionality problems. For this step, various ways of solving the multifunctionality problem have been proposed and applied, on the basis of mass, energy, economic value, avoided burdens, etc. As the GHG indicator may constitute the basis for granting subsidies to stimulate the use of bioenergy, for example, and as the method for the GHG indicator provides no guidelines on the handling of biogenic $\mathrm{CO}_{2}$ and guidelines for solving multifunctionality problems such as with coproducts and recycling that leave room for various choices, this study analyzed whether the current GHG indicator provides results that are a robust basis for granting such subsidies.

Results For the robustness check, a hypothetical case study on wood residue-based electricity was set up in order to illustrate what the effects of different solutions and choices for the two steps mentioned may be. The case dealt with the production of wood pellets (residues of the wood industry) that are cofired in a coal-fired power plant. The functional unit is $1 \mathrm{kWh}$ of electricity. Three possibilities for the places of the multifunctional process, two possibilities for whether or not to include biogenic $\mathrm{CO}_{2}$, and four possibilities for the allocation method were distinguished and calculated. Varying the options for these three choices in this way appears to have a huge effect on the GHG indicator, while no clear pattern seems to emerge.

Discussion The results found for this hypothetical case indicate that there are several methodological choices that have not sufficiently been fixed by the presently available standards and guidelines for LCA and GHG assessment of bioenergy systems. In particular, we have focused on issues 
related to biogenic $\mathrm{CO}_{2}$ and allocation, two issues that play a prominent role in the assessment of bioenergy systems. Moreover, we have demonstrated with a small hypothetical case study that these are not only issues that might theoretically show up, but that they play a decisive role in practice.

Conclusions The present (Dutch) GHG indicator lacks robustness, which will raise problems for providing a sound basis for granting subsidies. This situation can, however, be improved by reducing the freedom of choices for the handling of biogenic $\mathrm{CO}_{2}$ and allocation to an absolute minimum.

Recommendations and perspectives Even then, however, differences could appear due to different definitions, data sources, and method interpretations. It thus appears that two kinds of guidance are needed: (1) the LCA methodology itself should be expanded with guidelines for those issues that follow from science, logic, or consensus; (2) in the policy regulation that demands LCA to be the basis of the decision, additional guidelines should be specified that perhaps do not (yet) have the status of being scientifically proven or generally agreed upon, but that serve as a set of temporary extra guidelines.

Keywords Allocation - Bioelectricity - Biogenic $\mathrm{CO}_{2}$. Carbon footprint . Greenhouse gas indicator . LCA . Life cycle assessment

\section{Background, aim, and scope}

The expectations with respect to biomass as a resource for sustainable energy are sky-high. Many industrialized countries have adopted ambitious policy targets and have introduced financial measures to stimulate the production or use of bioenergy (e.g., Koplow 2006; Kutas et al. 2007). Reasons typically given for why bioenergy should be promoted are diverse: it stimulates the agricultural sector, it is carbon-neutral, it is made from renewable resources, and it may be produced domestically in many countries, hence diminishing political and economic dependency on foreign countries.

Meanwhile, the side-effects and associated risks have been pointed out as well (Doornbosch and Steenblik 2007; Boswell et al. 2007; Butler 2007). These potentially cover a wide spectrum of aspects: from a less favorable energy balance to the destruction of rain forests. They even potentially cover nonenvironmental aspects, such as the impact on food availability at affordable prices (Doornbosch and Steenblik 2007).

To be able to make a well-informed decision, the Dutch government has expressed its intention to include sustainability criteria into relevant policy instruments (Anonymous
2006). As a part of this, a method to calculate the life-cyclebased emissions of greenhouse gasses (GHG) has been proposed. A life-cycle-based GHG indicator (also known as a $\mathrm{CO}_{2}$ tool or carbon footprint) is calculated. Bergsma et al. (2006), the developers of the indicator, state in their report that life-cycle assessment (LCA), as described in the ISO standards (ISO 2006a, b), has been adopted for the calculation of this indicator. Although this is not completely true (e.g., it is restricted to climate change impacts only) (JRC-IES 2007), we will nevertheless adopt LCA and the associated ISO standards as reference for our further discussions below ${ }^{1}$.

\section{Goal and scope definition}

To estimate the percentage GHG reduction achieved by a particular biomass production chain, or biochain, its performance is compared with a reference fossil chain. The basic format for calculating the GHG reduction is, thus (Bergsma et al. 2006):

$$
\begin{aligned}
& \mathrm{GHG}_{\text {reduction }}(\%) \\
& \quad=\frac{\mathrm{GHG}_{\text {emission, fossil chain }}-\mathrm{GHG}_{\text {emission, biochain }}}{\mathrm{GHG}_{\text {emission, fossil chain }}} * 100
\end{aligned}
$$

Problems that show up persistently in LCAs of bioenergy and products from agriculture and forestry in general include:

- The handling of biogenic carbon balances (see, e.g., Rabl et al. 2007);

- The treatment of coproducts and recycling, e.g., in the cases of wood residues and manure (see, e.g., Curran 2007).

As it has been suggested by policy makers that the GHG indicator may constitute the basis for granting subsidies to stimulate the use of bioenergy, for example, it is of utmost importance that the indicator results be robust and "lawsuitproof." This implies that choices with respect to the problems mentioned above should be reduced to an absolute minimum. In Bergsma et al. (2006), as in the ISO standards, no guidelines on the handling of $\mathrm{CO}_{2}$ are provided, however, and the guidelines proposed for treating coproducts and recycling leave room for various choices. Thus, it is interesting to study to what extent a GHG indicator provides results that are a robust basis for granting subsidies.

\footnotetext{
${ }^{1}$ For the purpose of this article, we adopt the methods as defined in Bergsma et al. (2006) as they are without discussing what type of LCA methodology would be best to address the topic of bioenergy vs fossil energy.
} 
Below, we provide a theoretical discussion of these issues and use a hypothetical example on the generation of electricity from wood residues to illustrate the possible effect of this "freedom of choice" on the GHG indicator. For convenience, only $\mathrm{CO}_{2}$ emissions are taken into account ${ }^{2}$ and the fossil electricity reference system is simply taken to be $20 \mathrm{~kg} / \mathrm{kWh}$ without elaborate analysis of this reference system. Of course, the choice of the fossil reference system could be a study in itself and may introduce other discussions on the robustness of the GHG indicator. However, we focus here on the biomass productions chains.

Section 3 discusses the issue of biogenic carbon balances, and Section 4 addresses various issues related to coproduction and recycling. Section 5 introduces a hypothetical case study for which Section 6 gives the results. Section 7 concludes.

\section{Main features}

\subsection{Balancing carbon inputs and outputs}

In LCAs of agricultural products, a distinction between "negative" and "positive" emissions may be relevant. In particular, carbon dioxide, as a naturally occurring compound or an anthropogenic emission, takes part in the socalled geochemical carbon cycle.

The most appropriate way to treat carbon cycles is to view them as genuine cycles and, thus, at the systems level, to subtract the fixation of $\mathrm{CO}_{2}$ during tree growth from the $\mathrm{CO}_{2}$ emitted during waste treatment of discarded wood and to quantify the $\mathrm{CH}_{4}$ emitted. A detailed elaboration of this kind of short carbon cycle has been developed by Virtanen and Nillson (1993) in their study of paper board.

Thus, $\mathrm{CO}_{2}$ and $\mathrm{CH}_{4}$ emissions should be accounted for in their entirety for both bioenergy and fossil fuels. For bioenergy, agricultural practices or forestry may, for example, be important processes. During tree growth, a certain amount of atmospheric $\mathrm{CO}_{2}$ is fixed, but is ultimately released (as $\mathrm{CO}_{2}$ or $\mathrm{CH}_{4}$ ) when the wood is landfilled, is incinerated, or decays naturally. For fossil

\footnotetext{
${ }^{2}$ A full LCA would not be limited to $\mathrm{CO}_{2}$ only, but would also include other GHG emissions, as well as emissions contributing to other impacts such as stratospheric ozone depletion, acidification, photochemical ozone formation, human toxicity, and ecotoxicity, as well as resource depletion, land use impacts, etc. The GHG indicator is, by definition, limited to GHG emissions and, in our case study, we further simplify this to $\mathrm{CO}_{2}$ for convenience. It is our personal opinion, however, that the scope of impacts considered should be broader, since impacts related to bioenergy are broader than just GHG impacts. In this article, the GHG indicator as described aboveincluding its limitations-is, nevertheless, the starting point of analysis.
}

fuels, carbon fixation has taken place as a natural (in contrast to economic or industrial) process millions of years ago and atmospheric release of carbon in the form of $\mathrm{CO}_{2}$ and $\mathrm{CH}_{4}$ occurs when these fuels are burned due to application in an economic process.

The rationale behind this difference in treatment is that forestry (the process that fixates the $\mathrm{CO}_{2}$ ) is a unit process, just like steel production is an intentional activity, controlled by humans, requiring inputs and producing outputs. This is unlike the creation of fossil fuels, which were formed spontaneously millions of years ago, and without human intervention. The process of forestry is, thus, an activity that should be included in the flow diagram of an LCA study, whereas the process of fossil fuel formation should not.

Most guidebooks on LCA do not contain discussions on how to handle biogenic carbon balances, and neither do they include a guideline for how to handle sequestering ("negative emissions") of carbon dioxide. Also, Bergsma et al. (2006) provide no guidelines on short carbon cycles. Common practice in energy LCAs is that no explicit biogenic carbon balances are made, but that $\mathrm{CO}_{2}$ fixation during crop growth for bioenergy is set to zero, and the $\mathrm{CO}_{2}$ emission of incineration or digestion of the biofuel is also set to zero (Damen and Faaij 2006). In some cases, the part of $\mathrm{CO}_{2}$ fixated but released as $\mathrm{CH}_{4}$ may have been manually corrected by taking the full amount of biogenic $\mathrm{CH}_{4}$ into account, but this is not explicitly reported (Bergsma et al. 2006).

However, the issue of taking it into account more explicitly shows up in some exceptions. The Handbook on LCA by Guinée et al. (2002) states: "In agriculture, and particularly in forestry, sequestering of $\mathrm{CO}_{2}$ in biomass should be regarded as a negative emission, while $\mathrm{CO}_{2}$ or $\mathrm{CH}_{4}$ released during waste processing of the agricultural product should be considered a positive emission." This implies that these negative and positive emissions should be balanced against each other and that a full C-balance should be made for the systems considered. The widely used ecoinvent database (ecoinvent, 2004) ${ }^{3}$ distinguishes fossil $\mathrm{CO}_{2}$ from biogenic $\mathrm{CO}_{2}$. These do not automatically balance one another and can therefore not be canceled out. Rabl et al. (2007) discusses various cases where a full accounting of $\mathrm{CO}_{2}$ is useful. Ayres (1995) emphasizes an accounting of all flows for every unit process, to ensure that mass balances can be checked. Wegener Sleeswijk et al. (1996), in their report on the application of LCA to agricultural products, first propose (p.36) "not to include carbon dioxide in the analysis if the entire life cycle is

\footnotetext{
${ }^{3}$ In a newer version of ecoinvent (v2.0), a third category of $\mathrm{CO}_{2}$ emissions caused by land transformation is included (Jungbluth et al. 2007).
} 
being analysed," and then continue and argue that "if a socalled 'cradle-to-gate' analysis [...] is being performed, though, this fixation must either be included, or it must be explicitly stated that this fixation is being excluded from the study. If this is not done, there is a danger that if other researchers use the results of the study they will include, say, the emission of $\mathrm{CO}_{2}$ during combustion of biodiesel fuel, while fixation of $\mathrm{CO}_{2}$ was omitted in the cradle-togate analysis." Finally, the 2006 IPCC Guidelines for National Greenhouse Gas Inventories use as a reporting convention that "all emissions and removals ('negative' emissions) associated with a land-use change are reported in the new land-use category" (Aalde et al. 2006; see also Delucchi 2003 (S\&T) ${ }^{2}$ Consultants Inc, (2004)). Although the IPCC guidelines suggest a restriction to land-use change, further reading makes it clear that the reporting convention also encompasses the cultivation activity itself. Ayres (1995), Wegener Sleeswijk et al. (1996), and Aalde et al. (2006) can be regarded as a plea to include both negative and positive emissions of $\mathrm{CO}_{2}$, even for biogenic $\mathrm{CO}_{2}$.

An important question now is: does it matter whether one makes a full balance for biogenic carbon or not? Intuitively, one would think there would be no real difference. There are, however, situations where doing the accounting makes a real difference. An important case arises when product systems ${ }^{4}$ include multifunctional processes (coproduction, recycling, etc.). This case will be discussed in detail hereafter, and it will be illustrated in the hypothetical case study in Section 4.

\subsection{Multifunctionality and allocation}

There are a large number of processes that produce more than one function. This is increasingly the case in a society on the road towards sustainability, where use of coproducts and recycling play a prominent role, and where ecoindustrial parks are designed in a way that uses residual flows to an optimal extent. It is, incidentally, also an extremely ubiquitous situation in agriculture, where cow breeding produces milk, meat, leather, manure, and new calves, and where crop cultivation produces food for people, fodder for cattle, and residues that serve as soil fertilizers.

In LCAs of bioenergy, the production and use of coproducts and the recycling of waste figure prominently. Wood residues from timber production are used to generate electricity, and so is manure from poultry breeding. Incorporating coproducts in the modeling framework is therefore a critical issue.

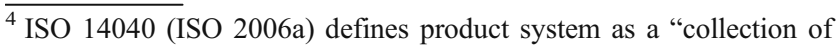
materially and energetically connected unit processes which perform one or more defined functions."
}

Handling of coproducts and recycling is captured in general under the headings of multifunctionality and allocation in LCA. The ISO standards provide a hierarchical approach for this; see Box 1.

Box 1 ISO 14044 allocation procedure (clause 4.3.4.2)

The study shall identify the processes shared with other product systems and deal with them according to the stepwise procedure presented below:

(a) Step 1: Wherever possible, allocation should be avoided by:

1. Dividing the unit process to be allocated into two or more subprocesses and collecting the input and output data related to these subprocesses

2. Expanding the product system to include the additional functions related to the coproducts...

(b) Step 2: Where allocation cannot be avoided, the inputs and outputs of the system should be partitioned between its different products or functions in a way that reflects the underlying physical relationships between them; i.e., they should reflect the way in which the inputs and outputs are changed by quantitative changes in the products or functions delivered by the system.

(c) Step 3: Where physical relationship alone cannot be established or used as the basis for allocation, the inputs should be allocated between the products and functions in a way that reflects other relationships between them. For example, input and output data might be allocated between coproducts in proportion to the economic value of the products.

Source: ISO 2006b.

Later elaborations by, e.g., Guinée et al. (2004) have provided more precise guidance, e.g., by stressing the importance of identifying the functional flows for every process, and by determining which processes should appear as multifunctional process in a flow diagram. In LCAs of bioenergy, these issues turn out to be extremely important.

The functional flows of a process are the inflows or outflows, or both, that constitute its goal, viz. the product outflows (including services) of a production process and the waste inflows of a waste treatment process. Observe that a flow is not intrinsically a functional flow, but only with respect to a certain unit process. To be specific, an outflow that is a functional flow for one unit process is a nonfunctional inflow for one or more other unit processes, and an inflow that is a functional flow for a specific unit process is a nonfunctional outflow for one or more other unit processes.

A multifunctional process is a unit process yielding more than one functional flow, i.e., coproduction, combined waste processing, and recycling:

- Coproduction: a multifunctional process having more than one functional outflow and no functional inflow

- Combined waste processing: a multifunctional process having no functional outflow and more than one functional inflow 
- Recycling: a multifunctional process having one or more functional outflows and one or more functional inflows (including cases of combined waste processing and coproduction simultaneously)

Guinée et al. (2002) distinguish two steps in solving the multifunctionality problem. The first concerns the modeling of the product system studied in the inventory analysis. In this step, system boundaries are set, processes are described, and process flows are quantified. Multifunctionality problems can be identified and the model of the product system is drafted. The better and more specific the model, the fewer multifunctionality problems will remain. For example, if the processes are specified to unit operation levels (e.g., individual machines), multifunctionality problems may be avoided in some specific cases. This is the starting step in the ISO allocation procedure (see text box above).

The second step concerns solving the remaining multifunctionality problems. For this step, various ways of solving the multifunctionality problem have been proposed and applied, on the basis of mass, energy, economic value, avoided burdens, etc. (see next section).

Let us first focus on the first step: identification of the multifunctionality problem. One of the first things to be determined then is which flows are the functional flows of a process. For this, the distinction between products (comprising goods, services, materials, and energy) and wastes is an essential step. ${ }^{5}$ To distinguish products from wastes, the economic value of flows is the determining property. A product is a flow between two processes with a positive economic value, whereas a waste is a flow between two processes with a negative economic value. ${ }^{6}$ Functional flows are either products that are produced by a process or wastes that are treated by a process. The functional flows of a specific unit process are the product outflows and the waste inflows. Thus, functional flows are the flows that generate revenue for the process for which they are a functional flow.

To determine, for process $\mathrm{A}$ in Fig. 1, if there is a multifunctionality problem, we need to know which of the three flows are functional flows. Flow 3 is not an economic flow, simply because it does not connect two unit processes but goes directly from a unit process into the environment, e.g., a river. This is an environmental or elementary flow and, therefore, not a functional flow, so it creates no multifunctionality problems. Assuming flow 1 has a positive economic value, everything then depends on the economic value of flow 2 . If the economic value of flow 2

\footnotetext{
$\overline{5}$ As early as 1871 , Jevons distinguished commodities from discommodities in his Theory of Political Economy.

${ }^{6}$ The exceptional case of flows with zero values are excluded from the present discussion.
}

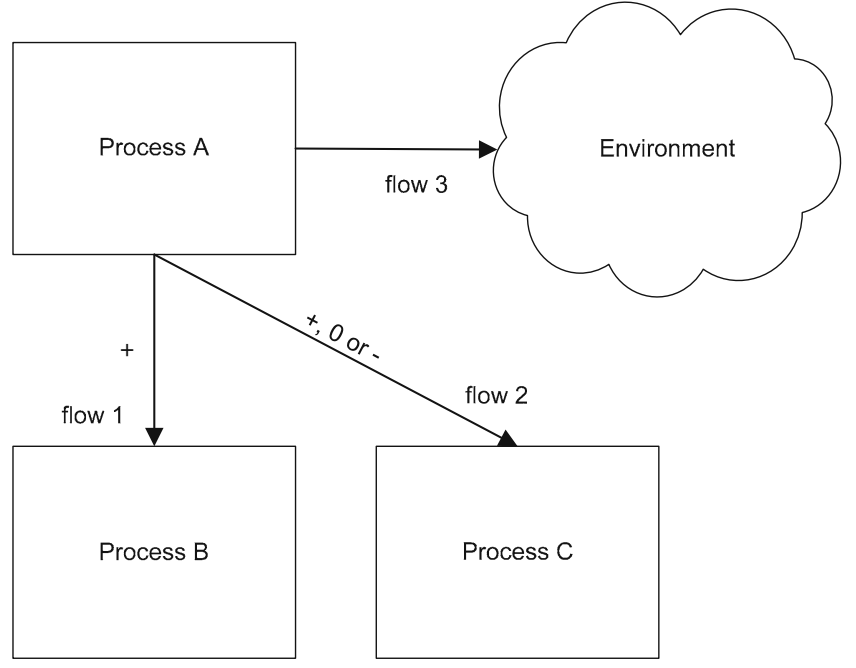

Fig. 1 Example of a potentially multifunctional process

is higher than zero as well, there is a multifunctionality problem that needs to be tackled in step 2 . If the economic value of flow 2 is smaller than zero, there is no multifunctionality problem, but flow 2 should be traced to a process that will manage this flow as waste. If such a process does not exist, the flow should be considered as one that has been cut off for reasons of data unavailability.

Then the second step: after the identification of the multifunctionality problem the remaining problems need to be solved. In Bergsma et al. (2006: pp 23-24), the guideline proposed to solve the multifunctionality problems is to apply "system extension"7 (hereafter "substitution"). Substitution here refers to expanding the product system with "avoided" processes (including upstream and downstream links) to remove additional functions related to the functional flows (i.e., coproducts or waste inflows). Substitution is well understood in principle but is often applied in quite different ways. Here, substitution has been applied at the level of the multifunctional process, meaning that a decision has to be made regarding which functional flow to include in the analysis and which functional flow(s) to remove by substitution. However, if substitution is not possible, other allocation methods may be deployed such as partitioning on an economic basis or partitioning on an energy basis. Partitioning refers to the act of splitting up a multifunctional process into several single-functional processes by means of so called allocation factors. In Fig. 1, with flow 2 having a positive economic value, this amounts to making a process that produces flow 1 and a fraction of

\footnotetext{
${ }^{7}$ System extension means extending the product system analyzed to include additional functions related to the coproducts. The system then includes more than one functional unit. The term "system extension" is sometimes used to refer to the substitution method, as in Bergsma et al., where substitution is actually recommended and not system extension.
} 
flow 3 , and a process that produces flow 2 and a fraction of flow 3. The fractions are determined by the allocation factors, and these, in their turn, can be based on mass ratios, energy ratios, ratios in proceeds, etc.

The guideline proposed by Bergsma et al. to solve the multifunctionality problems thus leaves room for choices. To analyze the possible effect of this "freedom of choice," we have performed sensitivity analyses on various (nonexhaustive) ways to solve the multifunctionality problem:

- Substitution on the basis of an avoided, hypothetical process

- Partitioning on a physical basis, in this case, on the basis of the carbon content (C-content) of the functional flows

- Partitioning on an economic basis using the shares in revenues (market prices $\times$ quantity of functional flows; see Guinée et al. 2004)

- The surplus method, which means ignoring additional functional flows that are not strictly needed for the product system under study. The coproduct is then ignored and all burdens are allocated to the main product

Systems extension has not been applied as in a comparative tool as the GHG indicator system extension does not work. The hypothetical system sketched in this article (see next section) produces as an expanded system "furniture" and "electricity." Another system that could be compared to this system may only produce electricity or furniture, and then these two alternative systems need to be made mutually comparable as yet applying substitution or allocation.

\section{A simple hypothetical example}

Let us assume the following hypothetical biofuel system for analysis of the sensitivity of the GHG indicator: the production of wood pellets (residues of the wood industry) that are cofired in a coal-fired power plant. A flow diagram of this hypothetical system is provided in Fig. 2. The functional unit is $1 \mathrm{kWh}$ of electricity. Several situations are possible now with respect to the prices of wood residues and pellets.

\subsection{Price situation 1}

If, in Fig. 2, wood residues have a positive economic value, the multifunctional process is "industrial processing" and the functional flows are "wood" and "wood residues." Industrial processing is then a coproduction process and the environmental interventions (i.e., emissions of $\mathrm{GHG}$ ) should be divided over the functional flows wood and wood residues. When applying substitution for this situation, wood residues is the functional flow needed for electricity production and, therefore, the functional flow wood is substituted.
Fig. 2 Flow diagram of the hypothetical production system of wood pellets (residues of the wood industry) that are cofired in a coal-fired power plant. The example is hypothetical, limited to $\mathrm{CO}_{2}$ only, and therefore, units are kilograms of $\mathrm{CO}_{2}$ and not kilograms of $\mathrm{CO}_{2}$-equivalents, and values for $\mathrm{CO}_{2}$ emissions are fictitious and rounded figures

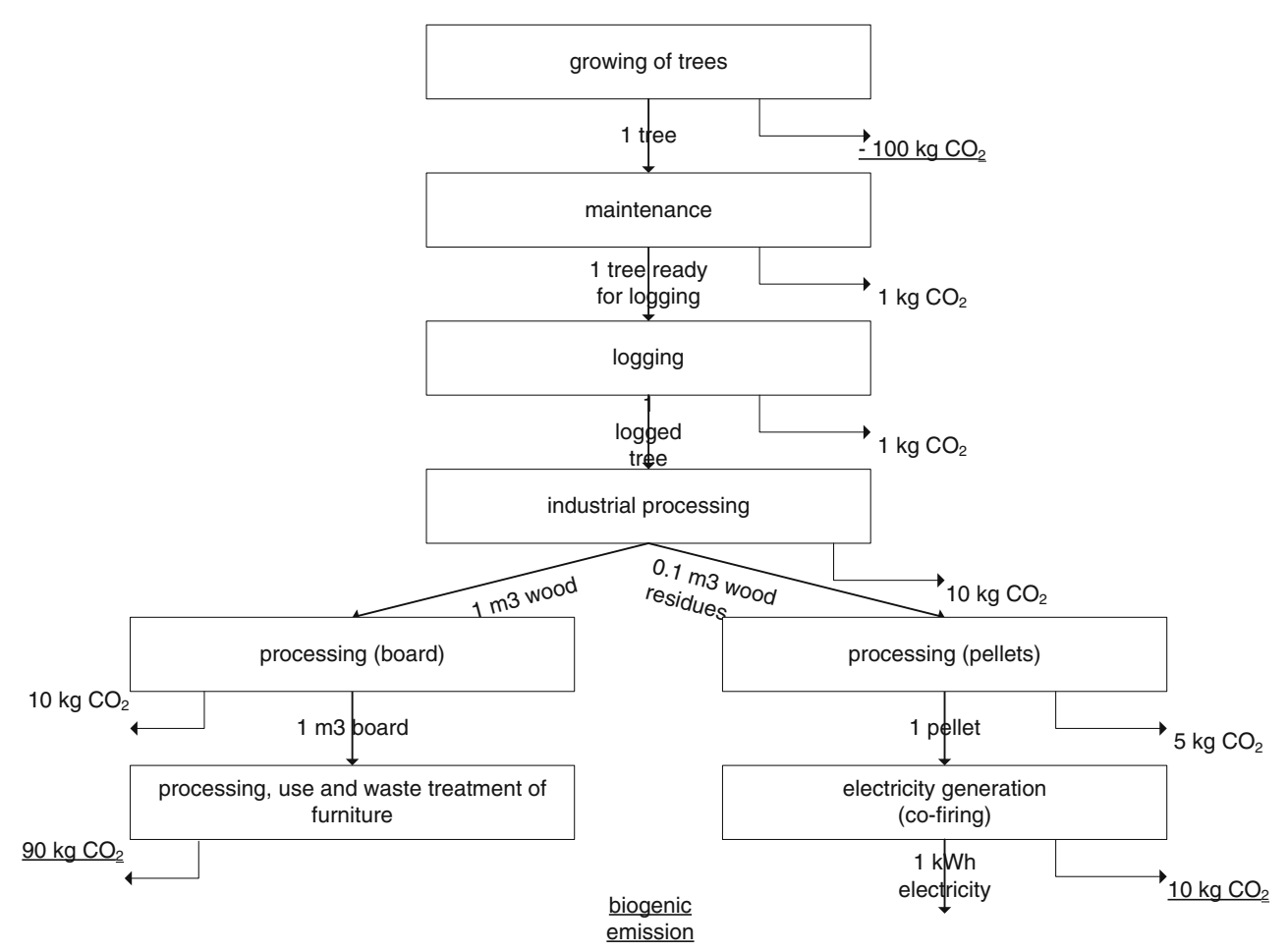


Table 1 Basic data for the multifunctional process "industrial processing" (price situation 1)

\begin{tabular}{|c|c|c|}
\hline & \multicolumn{2}{|c|}{ Functional flow } \\
\hline & Wood & Wood residues \\
\hline Quantity & $1 \mathrm{~m}^{3}$ & $0.1 \mathrm{~m}^{3}$ \\
\hline \multicolumn{3}{|l|}{ C-content allocation } \\
\hline C-content & $1 \mathrm{~kg} / \mathrm{m}^{3}$ & $1 \mathrm{~kg} / \mathrm{m}^{3}$ \\
\hline C-flow & $1 \mathrm{~kg}$ & $0.1 \mathrm{~kg}$ \\
\hline Allocation factor & 0.91 & 0.09 \\
\hline \multicolumn{3}{|l|}{ Economic allocation } \\
\hline Price $\left(€ / \mathrm{m}^{3}\right)$ & $9 € / \mathrm{m}^{3}$ & $2 € / \mathrm{m}^{3}$ \\
\hline Revenues $(€)$ & $9 €$ & $0.2 €$ \\
\hline Allocation factor & 0.9783 & 0.0217 \\
\hline \multicolumn{3}{|l|}{ Surplus method } \\
\hline \multicolumn{2}{|l|}{ Substitution } & 0 \\
\hline $\begin{array}{l}\text { Production of wood: reference system } \\
\text { A producing wood at the cost of }-75 \mathrm{~kg} \text { biogenic } \\
\mathrm{CO}_{2} / \mathrm{m}^{3} \text { wood and } 5 \mathrm{~kg} \mathrm{CO} 2 / \mathrm{m}^{3} \text { wood }\end{array}$ & \multicolumn{2}{|c|}{$\begin{array}{l}\mathrm{CO}_{2}(\mathrm{~kg}) \text { of unallocated system minus } \\
-70 \mathrm{~kg} \mathrm{CO} \mathrm{CO}_{2} \text { of reference system A }\end{array}$} \\
\hline
\end{tabular}

\subsection{Price situation 2}

A coproduction process is simple enough for illustrating the economic allocation procedure. Recycling processes, however, often create more problems, both conceptually and mathematically. If wood residues have a negative ${ }^{8}$ economic value and pellets have a positive economic value in Fig. 2, there are two processes that need a closer look: the "industrial processing" and "processing (pellets)." The industrial processing process has two outflows, of which, only one is a functional flow (in this case, product): wood. The other outflow of "wood residues" has a negative value and is, thus, a waste flow that should be traced down to its waste management process, in this case, processing (pellets). The inflow "logged tree" is a product; hence, this is not a functional flow. The processing (pellets) process provides a turning point for the economic value of the wood residues and pellet flows and, thus, we have an example of a multifunctional process, in this case, a recycling process. Thus, the process processing (pellets) needs to be partly allocated (division of 1 process only) to the system of the furniture (system 1) and partly to the system using the pellets (system 2). When applying substitution for this price situation, "pellet" is the functional flow needed for electricity production and, therefore, the functional flow "wood residues" is substituted.

\footnotetext{
${ }^{8}$ A negative economic value of wood residues may not be very likely in this day and age, but this example is rather to show the shifts in methods and results as a consequence of different economic values than to provide the precise current value of wood residues today.
}

\subsection{Price situation 3}

If wood residues and pellets both have negative economic values (see footnote 8) and electricity has a positive economic value, we have a slightly different situation from that in price situation 2. Now, not only the flow "wood residues" but also the flow "pellets" is negatively valued and is, thus, a waste flow which should be traced to a waste management process, i.e., "electricity generation (cofiring)". In this case, the "electricity generation (cofiring)" process provides a turning point for the economic value of the pellets and the electricity flows, and as the latter are used in other product systems, we have an example of recycling (waste pellets are "recycled" into electricity) again. Now, the process "electricity generation (cofiring)" needs to be partly allocated (division of 1 process only) to the pellets (part of system 1) and partly to electricity (part of system 2)When applying substitution for this price situation, "electricity" is the functional flow needed and therefore the functional flow "pellet" is substituted.

\section{Results}

Altogether, we have three possibilities for the places of the multifunctional process, two possibilities for whether or not to include biogenic $\mathrm{CO}_{2}$, and four possibilities for the allocation method. In this section, we present the results, first in terms of $\mathrm{CO}_{2}$ emissions allocated to the functional unit " $1 \mathrm{kWh}$ of electricity," and then in terms of the GHG indicator. The basic data for the multifunctional processes of the three price situations are summarized in Tables 1, 2, and 3. 
Table 2 Basic data for the multifunctional process "processing (pellets)" (price situation 2)

\begin{tabular}{|c|c|c|}
\hline & \multicolumn{2}{|c|}{ Functional flow } \\
\hline & pellet & wood residues \\
\hline Quantity & $1 \mathrm{p}$ & $-0.1 \mathrm{~m}^{3}$ \\
\hline \multicolumn{3}{|l|}{ C-content allocation } \\
\hline C-content & $1 \mathrm{~kg} / \mathrm{p}$ & $-1^{a} \mathrm{~kg} / \mathrm{m}^{3}$ \\
\hline C-flow & $1 \mathrm{~kg}$ & $1 \mathrm{~kg}$ \\
\hline Allocation factor & 0.91 & 0.09 \\
\hline \multicolumn{3}{|l|}{ Economic allocation } \\
\hline Price & $15 € / \mathrm{p}$ & $-15 € / \mathrm{m}^{3}$ \\
\hline Revenues & $15 €$ & $1.5 €$ \\
\hline Allocation factor & 0.909 & 0.091 \\
\hline \multicolumn{3}{|l|}{ Surplus method } \\
\hline $\begin{array}{l}\text { Allocation factor if } 100 \% \\
\text { allocated to wood residues } \\
\text { Substitution }\end{array}$ & 0 & 1 \\
\hline $\begin{array}{l}\text { Waste management of wood } \\
\text { residues: reference system B for } \\
\text { waste processing of wood residues } \\
\text { (landfill) at the cost of } 100 \mathrm{~kg} \mathrm{CO} 2 / \mathrm{m}^{3} \\
\text { wood residues }\end{array}$ & \multicolumn{2}{|c|}{$\begin{array}{l}\mathrm{CO}_{2}(\mathrm{~kg}) \text { of unallocated } \\
\text { system minus } 10 \mathrm{~kg} \mathrm{CO} \\
\text { of reference system B }\end{array}$} \\
\hline
\end{tabular}

${ }^{\mathrm{a}}$ Note that the minus does not mean that the $\mathrm{C}$-content is $<0$, but that the $\mathrm{C}$-outflow is negative. C-content allocation is, thus, not a correct term and should actually be replaced by $\mathrm{C}$-outflow allocation.

The calculations have been made with CMLCA (see http://www.leidenuniv.nl/cml/ssp/software/cmlca/index. $\mathrm{html}$ ), and the data files are available as electronic annexes: see Electronic Annex 1 in the online version of this article. The results are summarized in Tables 4 and 5 and in Fig. 3.

In Table 4, the resulting $\mathrm{CO}_{2}$ emissions allocated to $1 \mathrm{kWh}$ of electricity according to the three price situations have been summarized. In Table 5, the results of the calculations on the GHG indicator (Eq. 1) are presented for all methodological choices discussed in this article. In calculating the results for the GHG indicator, the $\mathrm{CO}_{2}$ emission for the fossil electricity reference system is simply taken to be $20 \mathrm{~kg} / \mathrm{kWh}$ for the sake of convenience. In Fig. 3, the results of Table 5 are presented in a graphical form.

\section{Discussion}

In this article, it has been argued that there are several methodological choices that have not sufficiently been fixed by the presently available standards and guidelines for LCA and GHG assessment of bioenergy systems. In particular, we have focused on issues related to biogenic $\mathrm{CO}_{2}$ and allocation, two issues that play a prominent role in the assessment of bioenergy systems. Varying the options for these issues for the three price situations appears to have a huge effect on the GHG indicator, and no clear pattern seems to emerge. Moreover, we have demonstrated with a small hypothetical case study that these are not only issues that might theoretically show up, but that they play a decisive role in practice. The current GHG indicator is highly sensitive for different choices as to handling of biogenic $\mathrm{CO}_{2}$ and the treatment of coproducts and recycling. Note that the GHG indicator for substitution may vary even more if different choices on what process or system would be substituted (questions like would bioenergy substitute for coal, oil or gas based energy?) would also be taken into account. Moreover, we have, for example, also included only one out of two surplus options in our calculations. Thus, there are many more possibilities to solve the multifunctionality problem and, consequently, many more fluctuations possible for the GHG indicator.

The fact that LCA results are sensitive for the choice of an allocation method is not new (Wang et al. 2004; Guinée and Heijungs 2007; Thomassen et al. 2008). The influence of the handling of biogenic $\mathrm{CO}_{2}$ on the GHG indicator is much more surprising and deserves further analysis. In Figs. 4, 5, and 6, the GHG indicator results for each price situation are compared for different allocation methods including and excluding biogenic $\mathrm{CO}_{2}$. For price situation 1 (Fig. 4), the differences for each allocation method including and excluding biogenic $\mathrm{CO}_{2}$ are huge, which is due to the fact that the full life cycle is partitioned through allocation over the functional flows wood and wood

Table 3 Basic data for the multifunctional process "electricity generation (cofiring)" (price situation 3)

\begin{tabular}{|c|c|c|}
\hline & \multicolumn{2}{|c|}{ Functional flow } \\
\hline & electricity & pellet \\
\hline Quantity & $1 \mathrm{kWh}$ & $-1 \mathrm{p}$ \\
\hline \multicolumn{3}{|l|}{ C-content allocation } \\
\hline C-content & $0 \mathrm{~kg} / \mathrm{kWh}$ & $-1 \mathrm{~kg} / \mathrm{p}$ \\
\hline C-flow & $0 \mathrm{~kg}$ & $1 \mathrm{~kg}$ \\
\hline Allocation factor & 0 & 1 \\
\hline \multicolumn{3}{|l|}{ Economic allocation } \\
\hline Price & $15 € / \mathrm{kWh}$ & $-10 € / \mathrm{p}$ \\
\hline Revenues & $15 €$ & $10 €$ \\
\hline Allocation factor & 0.6 & 0.4 \\
\hline \multicolumn{3}{|l|}{ Surplus method } \\
\hline $\begin{array}{l}\text { Allocation factor if } 100 \% \\
\text { allocated to pellet } \\
\text { Substitution }\end{array}$ & 0 & 1 \\
\hline $\begin{array}{l}\text { Waste management of pellet: } \\
\text { reference system } \mathrm{C} \text { for waste } \\
\text { processing of pellet at the cost } \\
\text { of } 10 \mathrm{~kg} \mathrm{CO} / \text { pellet }\end{array}$ & \multicolumn{2}{|c|}{$\begin{array}{l}\mathrm{CO}_{2}(\mathrm{~kg}) \text { of unallocated } \\
\text { system minus } 10 \mathrm{~kg} \mathrm{CO} \\
\text { of reference system C }\end{array}$} \\
\hline
\end{tabular}




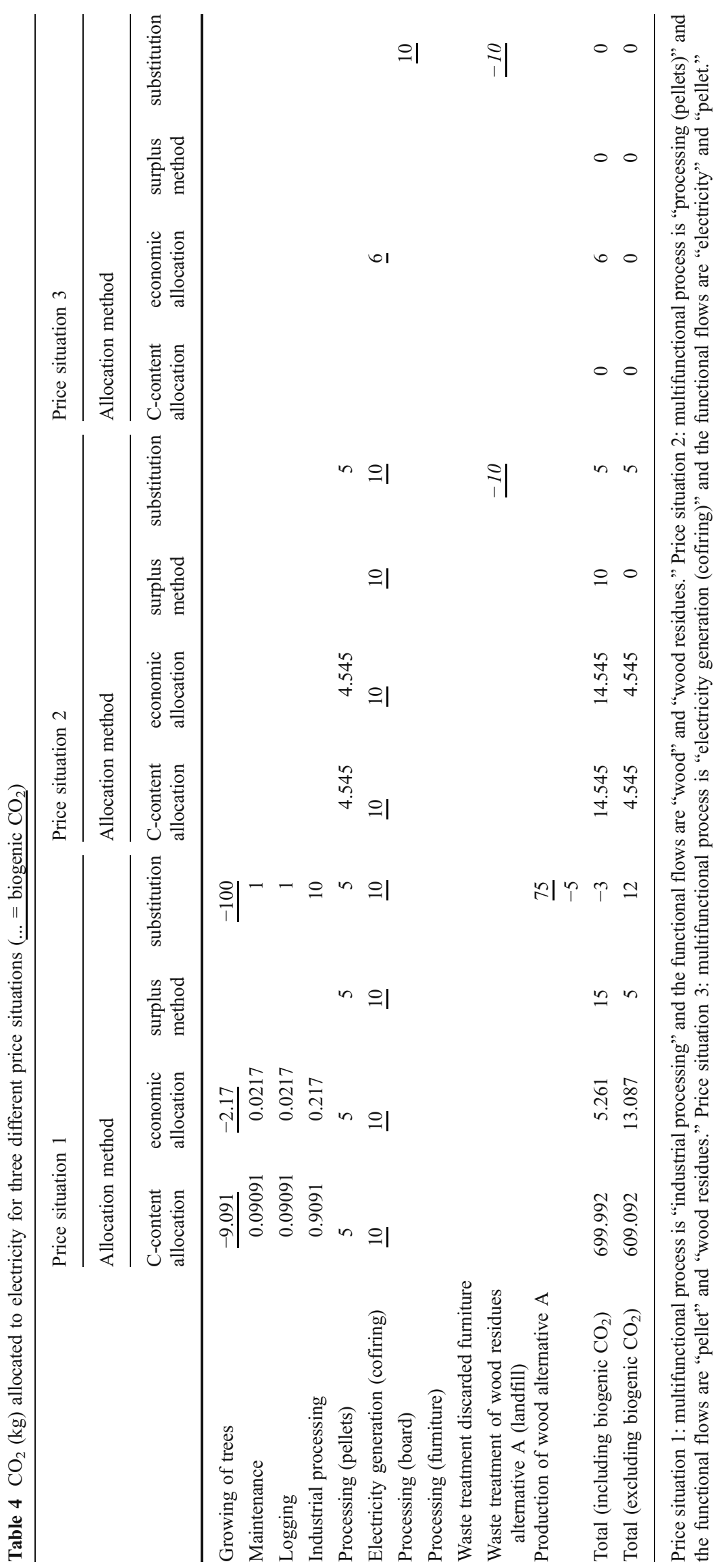


Table 5 Values of the GHG indicator for the different price situations and allocation methods

\begin{tabular}{|c|c|c|c|c|}
\hline \multirow[t]{2}{*}{ Price situation } & \multicolumn{4}{|l|}{ Allocation methods } \\
\hline & C-content allocation & Economic allocation & Surplus method & Substitution \\
\hline Price situation 1 , including biogenic $\mathrm{CO}_{2}$ & $65 \%$ & $35 \%$ & $25 \%$ & $115 \%$ \\
\hline Price situation 1 , excluding biogenic $\mathrm{CO}_{2}$ & $70 \%$ & $74 \%$ & $75 \%$ & $40 \%$ \\
\hline Price situation 2, including biogenic $\mathrm{CO}_{2}$ & $27 \%$ & $27 \%$ & $50 \%$ & $75 \%$ \\
\hline Price situation 2 , excluding biogenic $\mathrm{CO}_{2}$ & $77 \%$ & $77 \%$ & $100 \%$ & $75 \%$ \\
\hline Price situation 3 , including biogenic $\mathrm{CO}_{2}$ & $100 \%$ & $70 \%$ & $100 \%$ & $100 \%$ \\
\hline Price situation 3 , excluding biogenic $\mathrm{CO}_{2}$ & $100 \%$ & $100 \%$ & $100 \%$ & $100 \%$ \\
\hline
\end{tabular}

residues. As particularly "growing of trees" involves a large amount of fixated biogenic $\mathrm{CO}_{2}$ and, as this process is allocated differently to "wood" and "wood residues" according to the four allocation methods while the biogenic $\mathrm{CO}_{2}$ emission from "electricity generation (cofiring)" remains the same in all four allocation situations, the differences become huge. For price situation 2 (Fig. 5), the differences are also large. However, in this case, only the biogenic $\mathrm{CO}_{2}$ emission from "electricity generation (cofiring)," which is the same (it is no subject of allocation) for all four allocation situations, is the cause of these differences. The result for the substitution method, however, clearly differentiates for price situations 1 and 2 . This is merely a coincidence due to the chosen hypothetical data for the $\mathrm{CO}_{2}$ emissions of the substitution processes. For price situation 3 (Fig. 6), the differences are much smaller or even zero for three out of four allocation methods. This is due to the fact that, in this case, only a very small part of the life cycle, i.e., the process "electricity generation (cofiring)," needs to be partly allocated over the two functional flows "pellet" and "electricity." This discussion also clarifies that the GHG indicator results will significantly depend on the life cycle stages included in the analysis. For example, if tree growing and logging are left out of the analysis, the results will change roughly from the results for price situation 1 to the results for price situation 2. This supports the observation by Jungbluth et al. (2008; Chapter 9) that the calculated percentage of GHG reduction strongly depends on the life cycle stages included.

The results found for this hypothetical bioelectricity case have recently been confirmed by the first real-case results (Mendoza et al. 2008). As the GHG indicator is intended to be used, for example, by companies that generate electricity and heat using a biomass plant, and hope to receive a subsidy for this, the risk is currently very high that they will make different choices on these issues and that they may make the choices that best fit their purpose; the GHG
Fig. 3 Results of sensitivity calculations on the GHG indicator for three methodological choices

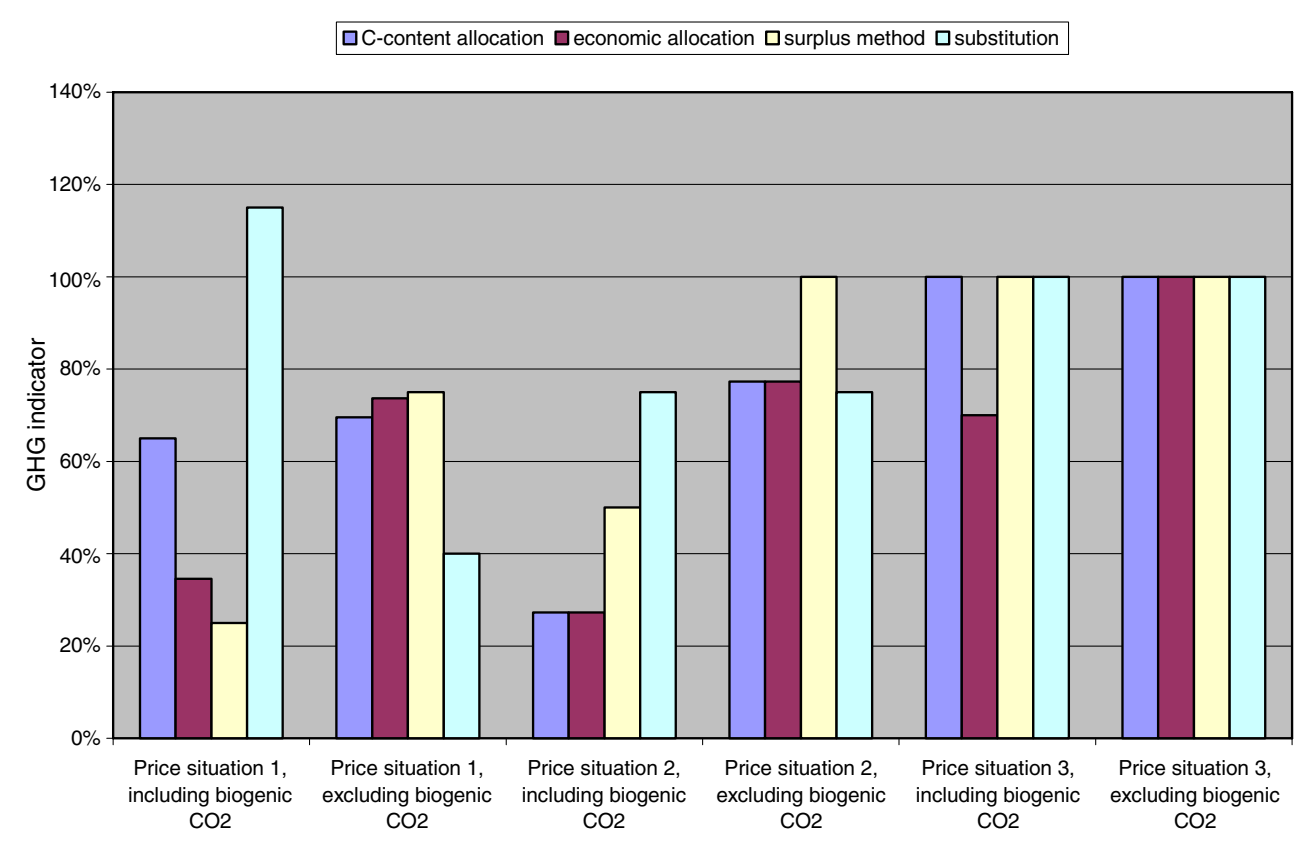




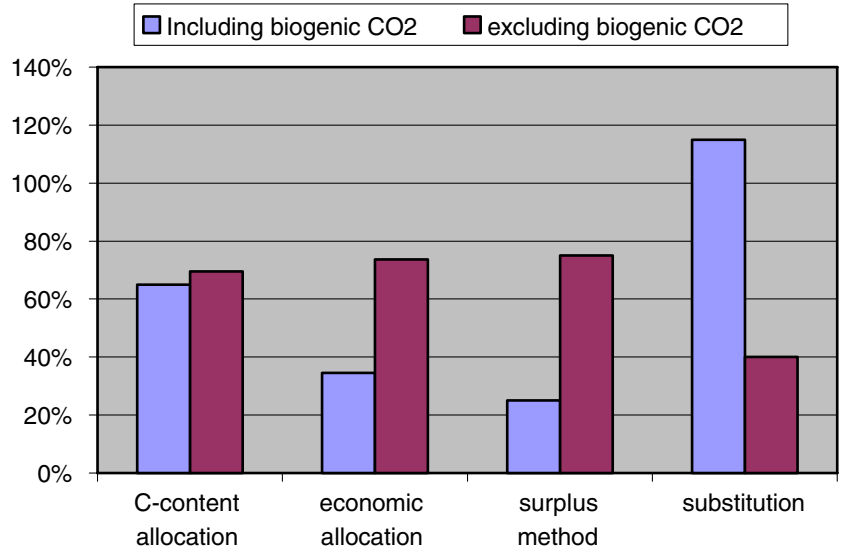

Fig. 4 GHG indicator results for price situation 1 for different allocation methods including and excluding biogenic $\mathrm{CO}_{2}$

indicator then becomes a "hired gun" instead of a proper basis for granting subsidies.

\section{Conclusions}

When something like a GHG indicator may constitute the basis for policy, e.g., granting subsidies to stimulate the use of bioenergy, it is of utmost importance that the indicator results be robust and "lawsuit-proof." It appears that the present indicator lacks this robustness, which will raise problems for providing a sound basis for granting subsidies and possibly also for other forms of bioenergy policy.

This does not mean that LCA is not suitable for such purposes. It only means that LCA in its present form, without a clear guidance on the treatment of biogenic $\mathrm{CO}_{2}$ and allocation, does not suffice. Some way to deal with this lack of guidance and robustness must therefore be found. This can be achieved by reducing the freedom of choices for the handling of biogenic $\mathrm{CO}_{2}$ and allocation to an

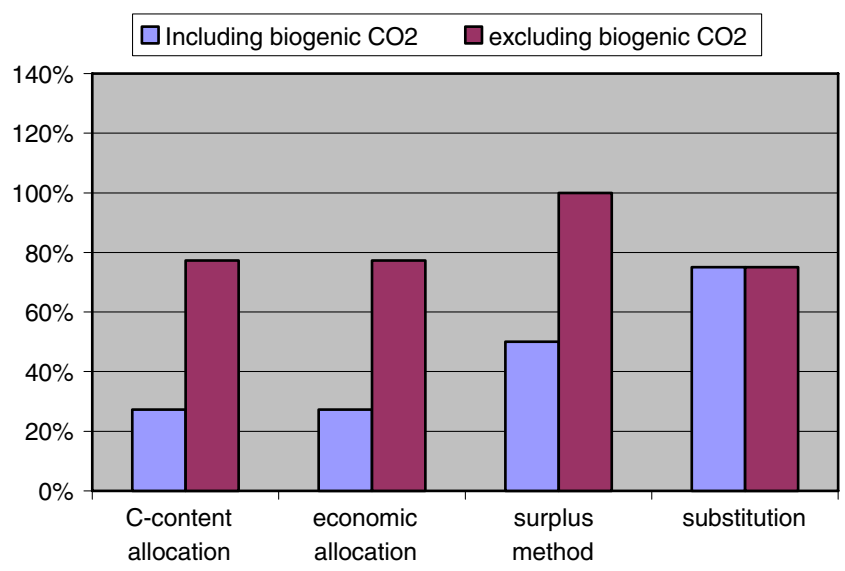

Fig. 5 GHG indicator results for price situation 2 for different allocation methods including and excluding biogenic $\mathrm{CO}_{2}$

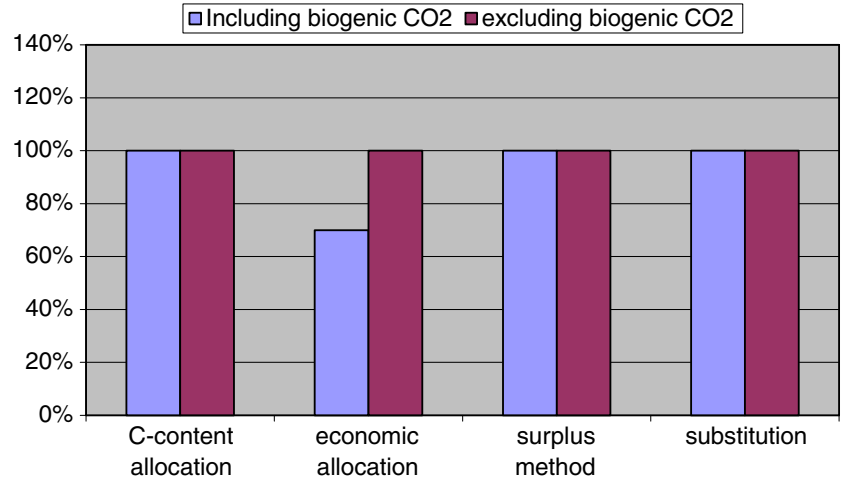

Fig. 6 GHG indicator results for price situation 3 for different allocation methods including and excluding biogenic $\mathrm{CO}_{2}$

absolute minimum. It should, for example, not be allowed to use a mixture of allocation methods, but the indicator calculations should all rather be based on one and the same method. Likewise, biogenic should be included as an input and as an output.

\section{Recommendations and perspectives}

Even then, however, differences could appear due to different definitions, data sources and method interpretations. Therefore, two kinds of guidance are recommended:

- The LCA methodology itself should be expanded with guidelines for those issues that follow from science, logic, or consensus. We think that the inclusion of biogenic $\mathrm{CO}_{2}$ is one such issue, where there are clear and compelling arguments (see Rabl et al. 2007).

- In the policy regulation that demands LCA to be the basis of the decision, additional guidelines should be specified that perhaps do not (yet) have the status of being scientifically proven or are generally agreed upon, but that serve as a set of temporary extra guidelines.

These two sets of further standardization guidelines allow us to separate the state of science from the requirements of unambiguous and robust policy for situations in which science does not (yet) offer an answer. This type of standardization along two lines is now getting more and more attention in several EU countries, for example, in the UK through the PAS (Publicly Available Specification) 2050 process (see http://www.bsi-global.com/upload/Standards $\%$ 20\&\%20Publications/PSS/Consultation_statement.pdf).

Acknowledgements The authors gratefully acknowledge SenterNovem (www.senternovem.nl) for enabling and financing this work as part of the project "Development and testing of a greenhouse gas calculation tool for biomass-based electricity and heat" (http://www. gave.novem.nl/figuur025/CO2_tool/CO2_tool.html\#punt1). Furthermore, one anonymous reviewer and Niels Jungbluth are gratefully acknowledged for their useful suggestions. 
Open Access This article is distributed under the terms of the Creative Commons Attribution Noncommercial License which permits any noncommercial use, distribution, and reproduction in any medium, provided the original author(s) and source are credited.

\section{References}

Aalde H, Gonzalez P, Gytarsky M, Krug T, Kurz WA, Lasco RD, Martino DL, McConkey BG, Ogle S, Paustian K, Raison J, Ravindranath NH, Schoene D, Smith P, Somogyi Z, van Amstel A, Verchot L (2006) Chapter 2: Generic methodologies applicable to multiple land-use categories. IPCC guidelines for national greenhouse gas inventories. Agriculture, forestry and other land use, vol 4. Intergovernmental Panel on Climate Change, Geneva

Anonymous (2006) Criteria voor duurzame biomassa productie. Eindrapport van de projectgroep "Duurzame productie van biomassa". Utrecht, the Netherlands: SenterNovem. https://www. senter.n1/mmfiles/Criteria_voor_duurzame_biomassa_productie Eindrapport_tcm24-200925.pdf. Accessed December 2007)

Ayres RU (1995) Life cycle analysis: a critique. Resour Conserv Recycl 14:199-223

Bergsma G, Vroonhof J, Dornburg V (2006) The greenhouse gas calculation methodology for biomass-based electricity, heat and fuels - The view of the Cramer Commission. Delft, the Netherlands: CE Delft Solutions for environment, economy and technology. http://www.senternovem.nl/mmfiles/methodologiegreenhousecal culethod_tcm24-239731.pdf. Accessed December 2007

Boswell A, Ernsting A, Rughani D (2007) Agrofuels threaten to accelerate global warming. Biofuelwatch. http://www.biofuelwatch.org.uk/biofuels_and_climate_change.pdf. Accessed December 2007

Butler RA (2007) Indonesian palm oil industry tries disinformation campaign. http://news.mongabay.com/2007/1108-palm_oil.html. Accessed December 2007

Curran MA (2007) Studying the effect on system preference by varying coproduct allocation in creating life-cycle inventory. Environ Sci Technol 41(20):7145-7151

Damen K, Faaij A (2006) A greenhouse gas balance of two existing international biomass import chains - the case of residue cofiring in a pulverised coal-fired power plant in the Netherlands. Mitig Adapt Strategies Glob Chang 11:1023-1050

Delucchi MA (2003) A lifecycle emissions model(lem): lifecycle emissions from transportation fuels, motor vehicles, transportation modes, electricity use, heating and cooking fuels, and materials. Documentation of methods and data. UCD-ITS-RR03-17. MAIN REPORT. Institute of Transportation Studies, University of California, Davis, CA 95616, USA. http://www. its.ucdavis.edu/people/faculty/delucchi/index.php\#Lifecycle Emissions

Doornbosch R, Steenblik R (2007) Biofuels: is the cure worse than the disease? Round Table on Sustainable Development, Organisation for Economic Co-operation and Development (OECD). OECD, Paris

ecoinvent Centre (2004) ecoinvent data v1.1, Final reports ecoinvent 2000 No. 1-15. CD-ROM, ISBN 3-905594-38-2. Swiss Centre for Life Cycle Inventories, Dübendorf.

Guinée JB, Gorrée M, Heijungs R, Huppes G, Kleijn R, de Koning A, van Oers L, Wegener Sleeswijk A, Suh S, Udo de Haes HA, de Bruijn JA, van Duin R, Huijbregts MAJ (eds) (2002) Handbook on life cycle assessment: Operational guide to the ISO standards.
Series: Eco-efficiency in industry and science. Kluwer Academic, Dordrecht

Guinée JB, Heijungs R, Huppes G (2004) Economic allocation: Examples and derived decision tree. Int J LCA 9(1):23-33

Guinée JB, Heijungs R (2007) Calculating the influence of allocation scenarios in fossil fuel chains. Int J LCA 12(3):173-180

International Organization for Standardization (2006a) Environmental management-Life cycle assessment-Principles and framework (ISO 14040:2006). International Organization for Standardization, Geneva

International Organization for Standardization (2006b) Environmental management—Life cycle assessment—Requirements and guidelines (ISO 14044:2006). Geneva, Switzerland. http://www.iso.org/iso/ iso_catalogue/catalogue_tc/catalogue_detail.htm?csnumber $=38498$

JRC-IES (2007) Carbon footprint-what it is and how to measure it. European Platform on Life Cycle Assessment. European Commission - Joint Research Centre, Institute for Environment and Sustainability. Ispra. http://lca.jrc.ec.europa.eu/Carbon_footprint.pdf

Jungbluth N, Chudacoff M, Dauriat A, Dinkel F, Doka G, Faist Emmenegger M, Gnansounou E, Kljun N, Schleiss K, Spielmann M, Stettler C, Sutter J (2007) Life Cycle Inventories of Bioenergy. Ecoinvent report No. 17, v2.0. ESU-services, Uster, Switzerland. www.ecoinvent.org

Jungbluth N, Büsser S, Frischknecht R, Tuchschmid M (2008) Ökobilanz von Energieprodukten: life cycle assessment of biomass-to-liquid fuels. ESU-services, Uster, Switzerland. http://www.bfe.admin.ch/ $\mathrm{php} / \mathrm{modules} / \mathrm{enet} / \mathrm{streamfile} \cdot \mathrm{php}$ ? file $=000000009552$. pdf\&name $=000000280006$

Koplow D (2006) Biofuels-At what cost? Government support for ethanol and biodiesel in the United States. Geneva, Switzerland: Global Subsidies Initiative (GSI), International Institute for Sustainable Development (IISD)

Kutas G, Lindberg C, Steenblik R (2007) Biofuels-At what cost? Government support for ethanol and biodiesel in the European Union. Geneva, Switzerland: Global Subsidies Initiative (GSI), International Institute for Sustainable Development (IISD)

Mendoza A, Ruijven T van, Vad K, Wardenaar T (2008) The allocation problem in bio-electricity chains. Report of a Project Group as part of the MSc. Industrial Ecology, Institute of Environmental Sciences (CML), Leiden, The Netherlands. http:// www.leidenuniv.nl/cml/ssp/students/mendoza_et_al/allocation bio_electricity.pdf

Rabl A, Benoist A, Bron D, Peuportier B, Spadaro JV, Zoughaib A (2007) How to account for $\mathrm{CO} 2$ emissions from biomass in an LCA. Int J LCA 12(5):281

$(\mathrm{S} \& \mathrm{~T})^{2}$ Consultants Inc (2004): GHGenius, A model for lifecycle assessment of transportation fuels. http://www.ghgenius.ca/

Thomassen MA, Dalgaard R, Heijungs R, de Boer I (2008) Attributional and consequential LCA of milk production. Int $\mathrm{J}$ LCA 13(4):339-349

Virtanen Y, Nilsson S (1993) Environmental impacts of waste paper recycling. International Institute for Applied Systems Analysis (IIASA) \& Earthscan, London

Wang M, Lee H, Molburg J (2004) Allocation of energy use in petroleum refineries to petroleum products; implications for lifecycle energy use and emission inventory of petroleum transportation fuels. Int J LCA 9(1):34-44

Wegener Sleeswijk A, Kleijn R, van Zeijts H, Reus JAWA, Meeuwsen-van Onna MJG, Leneman H, Sengers HHWJM (1996) Application of LCA to agricultural products. 1. Core methodological issues; 2. Supplement to the 'LCA Guide'; 3. Methodological background. Institute of Environmental Sciences (CML), Leiden 